\title{
Potential Prognostic Factors of Downstaging Following Preoperative Chemoradiation for High Rectal Cancer
}

\author{
MAXI TREDER ${ }^{1}$, RASMUS PEULICHE VOGELSANG ${ }^{2}$, STEFAN JANSSEN ${ }^{1,3}$, \\ STEVEN E. SCHILD ${ }^{4}$, NIELS HENRIK HOLLÄNDER ${ }^{5}$ and DIRK RADES ${ }^{1}$ \\ ${ }^{1}$ Department of Radiation Oncology, University of Lübeck, Lübeck, Germany; \\ ${ }^{2}$ Department of Surgery, Zealand University Hospital, Koge, Denmark; \\ ${ }^{3}$ Private Practice of Radiation Oncology, Hannover, Germany; \\ ${ }^{4}$ Department of Radiation Oncology, Mayo Clinic, Scottsdale, AZ, U.S.A.; \\ ${ }^{5}$ Department of Oncology and Palliative Units, Zealand University Hospital, Naestved, Denmark
}

\begin{abstract}
Background/Aim: Treatment for high rectal cancers, particularly the value of preoperative treatment, is controversial. In our previous study, downstaging by preoperative chemoradiation resulted in improved outcomes. The aim of the present study was to identify prognostic factors to predict which patients will achieve downstaging and may benefit from preoperative treatment. Patients and Methods: In 54 patients with locally advanced nonmetastatic high rectal cancer, 8 factors were evaluated for downstaging by preoperative chemoradiation including age, gender, carcinoembryonic antigen level, performance status, $T$-/N-category, UICC-stage (Union for International Cancer Control) and histological grade. Downstaging was defined as decrease by at least one UICC-stage. Results: Downstaging was achieved in 36 patients (67\%). Patients at UICC-stage III showed a trend for downstaging. Conclusion: The majority of patients with UICC-stage III tumors were downstaged and appear to benefit from preoperative chemoradiation. In general, the potential value of preoperative treatment for high rectal cancers needs further investigation.
\end{abstract}

The annual incidence of rectal cancer is $15-25 / 100,000$ in the European Union (1). These tumors are classified as low, middle or high rectal cancers depending on the distance from the anal

This article is freely accessible online.

Correspondence to: Professor Dirk Rades, MD, Department of Radiation Oncology, University of Lübeck, Ratzeburger Allee 160, 23562 Lübeck, Germany. Tel: +49 45150045401, Fax: +49 45150045404, e-mail: rades.dirk@gmx.net

Key Words: High rectal cancer, preoperative chemoradiation, downstaging, prognostic factors. verge. High rectal cancers require particular attention, because it is not yet clear whether these tumors should be treated as other rectal cancers with preoperative radiotherapy (usually $5 \times 5 \mathrm{~Gy}$ ) or chemoradiation (usually 45.0-50.4 Gy in 25-28 fractions plus concurrent chemotherapy with 5-fluorouracil or capecitabine) plus/minus postoperative chemotherapy or similar to colon cancers with surgery followed by postoperative chemotherapy (2-5).

The most common classification of rectal cancers with respect to their height is that of the European Society for Medical Oncology (ESMO) (1). According to this classification, high cancers are located 10.1-15.0 cm from the anal verge. Regarding the optimal treatment of high rectal cancers, there is a lack of studies focusing on this particular group. Randomized trials that included these patients have produced conflicting results regarding the value of preoperative radiotherapy or chemoradiation (2-5). In our previous study of patients with high rectal cancer, successful downstaging following preoperative chemoradiation was associated with improved local control (LC) and overall survival (OS) on both univariate and multivariate analyses, and with metastases-free survival (MFS) on univariate analysis (6). Considering these results, this study aimed to identify prognostic factors that can help identify patients, prior to the start of treatment, who are likely to achieve a successful downstaging renderding a more favorable prognosis. These patients may be candidates for preoperative treatment as in other rectal cancers.

\section{Patients and Methods}

In this retrospective study, 54 patients with locally advanced nonmetastatic high rectal cancer (10.1-15.0 cm from the anal verge) were evaluated for potential prognostic factors with respect to successful downstaging following preoperative chemoradiation. Some data of 53 of these patients were previously reported (6). Radiotherapy doses were 50.4 Gy $(5 \times 1.8$ Gy per week) in all but 
one patient who received $48.6 \mathrm{~Gy}$. Concurrent chemotherapy was given in 53 patients and generally consisted of two cycles of 5flourouracil or capecitabine alone $(n=51)$ or plus oxaliplatin $(n=2)$.

Eight pre-treatment factors were investigated for a potential association with successful downstaging including age at the beginning of preoperative treatment ( $\leq 65 v s . \geq 66$ years, median $=65.5$ ), gender, carcinoembryonic antigen level $(\leq 5 \mathrm{vs} .>5 \mathrm{ng} / \mathrm{ml})$, Karnofsky performance score (70-80 vs. 90-100), clinical primary tumor category (T-category) prior to preoperative treatment (cT2 vs. cT3 vs. cT4), clinical nodal category (N-category) prior to preoperative treatment (cN0 vs. cN1 vs. cN2), UICC-stage (UICC=Union for International Cancer Control) prior to preoperative treatment (II $v s$. III) and histologic grade ( $2 v s .3)$ (Table I). UICC-stage II is defined as T3 N0 M0 (no distant metastases), and UICC-stage III as T1-T4 N1-2 M0.

Successful downstaging was defined as a decrease by at least one stage according to UICC, pathologically confirmed on surgical specimens including removed primary tumor and lymph nodes. Analyses for associations with successful downstaging were performed with the chi-square test. $p$-Values of $<0.05$ were considered significant, and $p$-values of $<0.10$ were regarded as a trend.

\section{Results}

In the entire series, successful downstaging was achieved in 36 of 54 patients $(67 \%)$. Of the eight investigated factors, UICC-stage III prior to preoperative treatment showed a trend $(p=0.089)$ for an association with successful downstaging. The results of all investigated factors are summarized in Table II.

\section{Discussion}

New therapeutic approaches have been introduced in the treatment of locally advanced rectal cancers to improve the outcomes of patients presenting with this malignant disease (7-9). Such approaches include, for example, modern techniques of laparoscopic surgery, radiotherapy with a concomitant boost or new combinations of anticancer drugs. One of the greatest challenges is the optimal treatment of rectal cancers located in the upper third of this organ. One important question is how the upper third of the rectum and high rectal cancers should be defined. The most common classification has been suggested by the ESMO, which defined high rectal cancers as located between 10.1 and $15.0 \mathrm{~cm}$ from the anal verge (1). Another important question is whether these tumors should recieve preoperative radiotherapy or chemoradiation? A few randomized trials investigated the role of preoperative treatment for rectal cancers in general, but did not focus specifically on high rectal cancers. However, these trials produced contradictory results. The first trial was published in 2001. It included 533 patients with rectal cancers located at $10.1-15.0 \mathrm{~cm}$ from the anal verge representing $30 \%$ of the entire study cohort and compared surgery with upfront radiotherapy of $5 \times 5$ Gy to surgery alone (4). Local recurrence rates were $1.3 \%$ vs. $3.8 \%$ at 2 years $(p=0.17)$ and $3.7 \%$ vs. $6.2 \%$ at 5 years $(p=0.12)$
$(4,10)$. After 10 years, the positive effect of preoperative radiotherapy on local control increased with the distance from the anal verge in the entire cohort $(p=0.03)$, but not in patients with a negative resection margin $(p=0.62)(11)$. Another randomized trial included 908 patients and was published in 2005 (3). In those patients $(\mathrm{N}=243)$ with high rectal cancers (defined as $\geq 11 \mathrm{~cm}$ from the anal verge), overall local recurrence rates were $8 \%$ after $5 \times 5$ Gy followed by surgery and $12 \%$ after surgery alone $(p=0.3)$. In 2009 , another randomized trial of 1,350 patients was reported (5). Radiotherapy with $5 \times 5$ Gy followed by surgery was compared to surgery alone or, if circumferential resection margins were involved (i.e. $\leq 1 \mathrm{~mm}$ ), surgery followed by adjuvant 5-FU based chemoradiation. Of the entire cohort, 207 patients $(15 \%)$ had high rectal cancers $(10.1-15.0 \mathrm{~cm}$ form the anal verge). In this subgroup, the 3-year local recurrence rates were $1.2 \%$ in the preoperative radiotherapy group and $6.2 \%$ in the other group, respectively $(p<0.05)(5)$. In a subgroup analysis of patients with high rectal cancers (10.0$16.0 \mathrm{~cm}$ from the anal verge) from another randomized trial that included preoperative chemoradiation $(50.4 \mathrm{~Gy}$ in 28 fractions plus 2 concurrent cycles of $1000 \mathrm{mg} / \mathrm{m}^{2} 5$-FU given on 5 consecutive days), the 5 -year local recurrence rates were $2.5 \%$ in patients receiving preoperative chemoradiation $(\mathrm{N}=83)$ and $10.4 \%$ in those patients not receiving pre- and postoperative chemoradiation (12).

Studies focusing on high rectal cancers are urgently required. In our preceding retrospective study of locally advanced high rectal cancer (mainly stage III) located 10.0$15.0 \mathrm{~cm}$ from the anal verge, preoperative chemoradiation resulted in promising outcomes with 5-year LC, MFS and OS rates of $90 \%, 79 \%$ and $77 \%$, respectively, and was well tolerated (6). Grade 3 acute toxicities were observed in $19 \%$ of the patients compared to $27 \%$ of grade 3 or 4 toxicities occurring in the German trial that mainly included tumors located within $9.9 \mathrm{~cm}$ from the anal verge $(2,6)$. Grade 3-4 late toxicities were $0 \%$ in our previous study and $14 \%$ in the German trial. However, the rate of perioperative complications such as anastomotic leakage (20\% vs. $11 \%)$ and wound healing problems (14\% vs. 10\%) were more frequent in our previous study than in the randomized trial from Germany, although the quality of surgery in our previous study was high (100\% microscopically complete resections with wide margins of median $20 \mathrm{~mm})(2,6)$. The higher complication rate is an argument against preoperative chemoradiation.

However, in our previous study, it was found that downstaging by at least one UICC-stage by chemoradiation resulted in significantly better outcomes in terms of LC and OS. Successful downstaging may be a surrogate marker for better prognoses. However, this finding may also contribute to the identification of patients who benefit from preoperative chemoradiation, if it was possible to predict the 
Table I. Characteristics of the 54 patients.

\begin{tabular}{lc}
\hline Characteristic & Number of patients $(\%)$ \\
\hline Gender & \\
Female & $25(46)$ \\
Male & $29(54)$ \\
Age at start of radiotherapy & \\
$\leq 65$ Years & $27(50)$ \\
$\geq 66$ Years & $27(50)$ \\
Karnofsky performance score & \\
$70-80 \%$ & $10(19)$ \\
$90-100 \%$ & $20(37)$ \\
Unknown & $24(44)$ \\
Carcinoembryonic antigen - level & \\
$\leq 5$ ng/ml & $27(50)$ \\
$>5$ ng/ml & $12(22)$ \\
Unknown & $15(28)$ \\
Clinical primary tumor category & \\
cT2 & $3(6)$ \\
cT3 & $46(85)$ \\
cT4 & $5(9)$ \\
Clinical primary tumor category & \\
cN0 & $12(22)$ \\
cN1 & $34(63)$ \\
cN2 & $8(15)$ \\
UICC-stage prior to radiotherapy & \\
Stage II & $12(22)$ \\
Stage III & $42(78)$ \\
Histologic grading & \\
Grade 2 & $46(85)$ \\
Grade 3 & $7(13)$ \\
Unknown & $1(2)$ \\
\hline
\end{tabular}

UICC: Union for International Cancer Control.

probability of successful downstaging prior to the start of treatment. Therefore, our current study aimed to identify predictors of downstaging in a cohort of patients with high rectal cancers receiving preoperative chemoradiation. According to its results, pre-treatment of patients at UICCstage III showed a trend for an association with downstaging. Thus, patients with stage III high rectal cancers may benefit from preoperative chemoradiation. Due to the limitations of this study, i.e. its retrospective design and the relatively small number of patients, this conclusion needs to be further evaluated in a larger cohort of patients. Furthermore, studies that compare preoperative chemoradiation followed by surgery plus/minus postoperative chemotherapy to surgery followed by chemotherapy are urgently required to identify the optimal treatment of patients with high rectal cancers.

In summary, in the majority of patients with UICC-stage III tumors preoperative chemoradiation led to successful downstaging. These patients may benefit from preoperative treatment. However, the potential value of preoperative treatment for high rectal cancers should be further evaluated.
Table II. Patient characteristics related to successful downstaging.

\begin{tabular}{|c|c|c|c|}
\hline Characteristic & $\begin{array}{c}\text { No succesful } \\
\text { downstaging } \\
\text { N patients } \\
(\%)\end{array}$ & $\begin{array}{c}\text { Succesful } \\
\text { downstaging } \\
\text { N patients } \\
(\%)\end{array}$ & $p$-Value \\
\hline \multicolumn{4}{|l|}{ Gender } \\
\hline Female & $8(32)$ & $17(68)$ & \\
\hline Male & $10(34)$ & $19(66)$ & 0.89 \\
\hline \multicolumn{4}{|c|}{ Age at start of radiotherapy } \\
\hline$\leq 65$ Years & $9(33)$ & $18(67)$ & \\
\hline$\geq 66$ Years & $9(33)$ & $18(67)$ & 1.00 \\
\hline \multicolumn{4}{|c|}{ Karnofsky performance score } \\
\hline $70-80 \%$ & $5(50)$ & $5(50)$ & \\
\hline $90-100 \%$ & $8(40)$ & $12(60)$ & 0.68 \\
\hline \multicolumn{4}{|c|}{$\begin{array}{l}\text { Carcinoembryonic } \\
\text { antigen - level }\end{array}$} \\
\hline$\leq 5 \mathrm{ng} / \mathrm{ml}$ & $9(33)$ & $18(67)$ & \\
\hline$>5 \mathrm{ng} / \mathrm{ml}$ & $5(42)$ & $7(58)$ & 0.69 \\
\hline \multicolumn{4}{|c|}{$\begin{array}{l}\text { Clinical primary } \\
\text { tumor category }\end{array}$} \\
\hline cT2 & $0(0)$ & $3(100)$ & \\
\hline cT3 & $17(37)$ & $29(63)$ & \\
\hline $\mathrm{cT} 4$ & $1(20)$ & $4(80)$ & 0.48 \\
\hline \multicolumn{4}{|c|}{$\begin{array}{l}\text { Clinical primary } \\
\text { tumor category }\end{array}$} \\
\hline cNO & $7(58)$ & $5(42)$ & \\
\hline $\mathrm{cN} 1$ & $9(26)$ & $25(77)$ & \\
\hline $\mathrm{cN} 2$ & $2(25)$ & $6(75)$ & 0.23 \\
\hline \multicolumn{4}{|c|}{$\begin{array}{l}\text { UICC-stage prior to } \\
\text { radiotherapy }\end{array}$} \\
\hline Stage II & $7(58)$ & $5(42)$ & \\
\hline Stage III & $11(26)$ & $31(74)$ & 0.089 \\
\hline \multicolumn{4}{|c|}{ Histologic grading } \\
\hline Grade 2 & $15(33)$ & $31(67)$ & \\
\hline Grade 3 & $3(43)$ & $4(57)$ & 0.68 \\
\hline
\end{tabular}

UICC: Union for International Cancer Control; bold values: $p$-values representing at least a trend.

\section{Conflicts of Interest}

On behalf of all Authors, the corresponding Author states that there is no conflict of interest related to this study.

\section{Acknowledgements}

The study was part of the project InnoCan, which is funded by Interreg Deutschland-Danmark with funds from the European Regional Development Fund.

\section{References}

1 Glynne-Jones R, Wyrwicz L, Tiret E, Brown G, Rödel C, Cervantes A, Arnold D and ESMO Guidelines Committee: Rectal cancer: ESMO Clinical Practice Guidelines for diagnosis, treatment and follow-up. Ann Oncol 28: iv22-iv40, 2017. 
2 Sauer R, Becker H, Hohenberger W, Rödel C, Wittekind C, Fietkau R, Martus P, Tschmelitsch J, Hager E, Hess CF, Karstens JH, Liersch T, Schmidberger H and Raab R; German Rectal Cancer Study Group: Preoperative versus postoperative chemoradiotherapy for rectal cancer. N Engl J Med 351: 17311740, 2004.

3 Folkesson J, Birgisson H, Pahlman L, Cedermark B, Glimelius B and Gunnarsson U: Swedish Rectal Cancer Trial: long lasting benefits from radiotherapy on survival and local recurrence rate. J Clin Oncol 23: 5644-5650, 2005.

4 Kapiteijn E, Marijnen CA, Nagtegaal ID, Putter H, Steup WH, Wiggers T, Rutten HJ, Pahlman L, Glimelius B, van Krieken JH, Leer JW and van de Velde CJ; Dutch Colorectal Cancer Group: Preoperative radiotherapy combined with total mesorectal excision for resectable rectal cancer. N Engl J Med 345: 638-646, 2001.

5 Sebag-Montefiore D, Stephens RJ, Steele R, Monson J, Grieve R, Khanna S, Quirke P, Couture J, de Metz C, Myint AS, Bessell E, Griffiths G, Thompson LC and Parmar M: Preoperative radiotherapy versus selective postoperative chemoradiotherapy in patients with rectal cancer (MRC CR07 and NCIC-CTG C016): a multicentre, randomised trial. Lancet 373: 811-820, 2009.

6 Treder M, Janssen S, Holländer NH, Schild SE and Rades D: Role of neoadjuvant radio-chemotherapy for the treatment of high rectal cancer. Anticancer Res 38: 5371-5377, 2018.

7 Nonaka T, Fukuda A, Maekawa K, Nagayoshi S, Tokunaga T, Takatsuki M, Kitajima T, Taniguchi K and Fujioka H: Clinical and oncological outcomes of laparoscopic versus open surgery for advanced rectal cancer. Anticancer Res 36: 5419-5424, 2016.

8 Picardi V, Deodato F, Guido A, Giaccherini L, Macchia G, Gambacorta MA, Arcelli A, Farioli A, Cellini F, Cuicchi D, DI Fabio F, Poggioli G, Ardizzoni A, Frezza G, Cilla S, Caravatta L, Valentini V, Fuccio L and Morganti AG: Concurrent chemoradiation with concomitant boost in locally advanced rectal cancer: A phase II study. Anticancer Res 36: 4081-4087, 2016.
9 Chien CR, Chen WT, Wang HM, Ke TW, Chiang HC, Chang SC, Huang YC, Lin CH, Huang CL, Lin YC, Chen TW, Li CC and Chao KS: A Comparative effectiveness study of two oral chemotherapy drugs (UFT vs. capecitabine) in neoadjuvant concurrent chemoradiotherapy for patients with locally advanced rectal cancer. Anticancer Res 36: 6155-6160, 2016.

10 Peeters KC, Marijnen CA, Nagtegaal ID, Kranenbarg EK, Putter H, Wiggers T, Rutten H, Pahlman L, Glimelius B, Leer JW and van de Velde CJ; Dutch Colorectal Cancer Group: The TME trial after a median follow-up of 6 years: increased local control but no survival benefit in irradiated patients with resectable rectal carcinoma. Ann Surg 246: 693-701, 2007.

11 van Gijn W, Marijnen CA, Nagtegaal ID, Kranenbarg EM, Putter H, Wiggers T, Rutten HJ, Påhlman L, Glimelius B and van de Velde CJ; Dutch Colorectal Cancer Group: Preoperative radiotherapy combined with total mesorectal excision for resectable rectal cancer: 12-year follow-up of the multicentre, randomised controlled TME trial. Lancet Oncol 12: 575-582, 2011.

12 Sauer R, Liersch T, Merkel S, Fietkau R, Hohenberger W, Hess C, Becker H, Raab HR, Villanueva MT, Witzigmann H, Wittekind C, Beissbarth T and Rödel C: Preoperative versus postoperative chemoradiotherapy for locally advanced rectal cancer: results of the German CAO/ARO/AIO-94 randomized phase III trial after a median follow-up of 11 years. J Clin Oncol 30: 1926-1933, 2012.
Received August 9, 2018

Revised September 21, 2018

Accepted September 28, 2018 